\title{
Cloning and functional expression of the equine luteinizing hormone/chorionic gonadotrophin receptor
}

\author{
Marie Saint-Dizier, Florence Foulon-Gauze, François Lecompte, \\ Yves Combarnous and Maryse Chopineau
}

Unité de Physiologie de la Reproduction et des Comportements, UMR 6175 INRA-CNRS-Université F. Rabelais de Tours-Haras Nationaux, 37380 Nouzilly, France.

(Requests for offprints should be addressed to Marie Saint-Dizier; Email: stdizier@inapg.fr)

(M Saint-Dizier is now at UMR 1198 INRA/ENVA Biologie du Développement et Reproduction, Institut National Agronomíque de Paris-Grignon, Dept. des Sciences Animales, 16 rue Claude Bernard, 75235 Paris Cedex 05, France)

\begin{abstract}
Pituitary equine luteinizing hormone (eLH) and fetal chorionic gonadotrophin (eCG) have identical polypeptidic chains, but different linked carbohydrates. In equine tissues, eCG and eLH bind only to the LH/CG receptor (eLH/CG-R) and have no FSH activity. However, radioreceptor assays on equine luteal or testicular tissues have shown that eCG binds to the eLH/CG-R with only $2-4 \%$ of the binding activity of eLH. In order to study the structure-function relationship of eLH and eCG in a homologous sytem, we undertook the cloning and functional expression of the eLH/CG-R.

Based on sequence homologies among mammalian sequences for the LH/CG-R, overlapping partial fragments of LH/CG-R cDNAs were obtained from mare luteal RNA using reverse transcription-PCR and $5^{\prime}$-rapid amplification of cDNA ends. Ligations of the partial cDNA fragments encoded a part of the signal peptide followed by a putative 672 amino acid eLH/CG-R mature protein. The mature eLH/CG-R displayed $88 \cdot 2-$ $92 \cdot 8 \%$ overall sequence homology with the other mam-
\end{abstract}

malian LH/CG-Rs and contained one unique seventh $\mathrm{N}$-glycosylation site in its extracellular domain.

COS-7 cells were transiently transfected with a cDNA construct encoding an engineered complete signal peptide and the mature eLH/CG-R. Membrane preparations from transfected COS-7 cells bound ${ }^{125} \mathrm{I}-\mathrm{eLH}$ with high affinity $\left(K_{\mathrm{d}} 3.8 \times 10^{-10} \mathrm{M}\right)$. On a molar basis, eCG competed with ${ }^{125} \mathrm{I}$-eLH on membrane preparations with only $12 \cdot 4 \%$ of the eLH binding activity. In transfected COS-7, both eLH and eCG increased the extracellular cAMP concentration in a dose-dependent manner, whereas eFSH did not. Furthermore, on a molar basis, eCG stimulated cAMP production with only $13.9 \%$ of the eLH stimulating activity.

We conclude that the cloned cDNA encodes a functional eLH/CG-R. The differences between eLH and eCG activities towards this receptor will be useful in studies of the influence of carbohydrates on gonadotrophin receptor binding and activation.

Journal of Endocrinology (2004) 183, 551-559

\section{Introduction}

The luteinizing hormone/chorionic gonadotrophin receptor (LH/CG-R), together with those of folliclestimulating hormone (FSH) and thyroid-stimulating hormone, belong to a subfamily of glycoprotein hormone receptors among the G-protein-associated seventransmembrane-domain receptors (Dufau 1998, Ascoli et al. 2002). The LH/CG-R has an important role in reproductive physiology: it is primarily expressed in the gonads, and it targets the action of LH to Leydig cells in the testis and to thecal, granulosa and luteal cells in the ovary. In primates during pregnancy, the LH/CG-R also targets the action of chorionic gonadotrophin in luteal cells, male human fetal gonads and other potential target organs that express LH/CG-R cDNA (Rao 1997, Themmen \& Huhtaniemi 2000). The main intracellular signalling pathway activated by the LH/CG-R is the adenylyl cyclase pathway, leading to an increase in intracellular cAMP (Dufau 1998, Ascoli et al. 2002).

Radioreceptor assays performed on luteal membranes from cyclic and pregnant mares have revealed that the equine (e) LH/CG-R, like the primate one, binds two distinct hormones: pituitary eLH and fetal eCG (Stewart \& Allen 1979, Ascoli et al. 2002). Furthermore, whereas eLH and eCG bind to both LH/CG and FSH receptors in all mammals studied, they have only an LH activity in equine tissues (Licht et al. 1979, Stewart \& Allen 1979, 1981, Guillou \& Combarnous 1983). Nevertheless, eCG binds to the eLH/CG-R with only $2-4 \%$ of the activity of eLH 
Table 1 Nucleic acid sequences of primers used for the isolation and cloning of the eLH/CG-R cDNA. Location of nucleotides corresponds to the eLH/CG-R cDNA sequence on Fig. 1B. Primer P4 is a degenerate primer in which $B=T / G / C, Y=C / T, K=T / G$ and $\mathrm{R}=\mathrm{A} / \mathrm{G}$

Location

\section{Name and orientation}

P1 (sense)

P2 (antisense)

P3 (sense)

P4 (antisense)

P5 (antisense)

P6 (sense)
203-224
$829-849$
$627-651$
2076-2112
$501-525$
$[-8]-71$

Sequence

\author{
5'-CTTTCAGAGGACTTAATGAGGT-3' \\ 5'-TCTAAAAGCACAGCAGTGGCT-3' \\ 5'-GCTGGAGAAGATGCACAACGGAGCC-3' \\ 5'-GCTCTAGACAGTTAACABTCYKTRTAGCRAGTCTTG-3' \\ 5'-TTCGTTATTCATCССТTGAAAAGCA-3' \\ 5'-GCTCTAGAATGAGAAGAAGGTCACTAGCACTACGACTATT

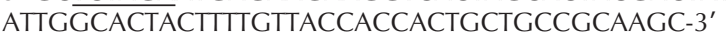

on testicular or luteal membranes from cyclic or pregnant mares (Stewart \& Allen 1979, Guillou \& Combarnous 1983, Saint-Dizier et al. 2003). In contrast, eCG and eLH display similar affinity toward the porcine LH-R (Guillou \& Combarnous 1983). Thus it is of interest to determine whether this difference in binding affinities is attributable to differences in $\mathrm{LH}$ receptor sequences.

The protein structure of eCG is completely identical to that of eLH (Bousfield et al. 1987, Sugino et al. 1987), as a single gene encodes for their $\alpha$-subunits (Stewart et al. 1987 ) and another gene encodes for their $\beta$-subunits (Sherman et al. 1992). Therefore, the differences in binding activity between eLH and eCG are likely to result from differences in size and structure of the $N$ - and $O$-glycan chains linked to the polypeptidic $\alpha$ - and $\beta$-chains. Indeed, eCG contains much more and bulkier carbohydrates than eLH (Bousfield et al. 1996, 2001). Furthermore, glycan chains on eCG are mainly terminated by sialic acids, whereas more than $72 \%$ of eLH glycan chains are sulphated (Smith et al. 1993). It has been shown that the O-linked oligosaccharides of eCG have a negative influence on eCG binding activity tested on rat testicular membranes (Butnev et al. 1996, Bousfield et al. 2001). However, the significance of eLH and eCG carbohydrates in eLH/CG-R binding activity remains to be investigated. Furthermore, the possible influence of eLH and eCG carbohydrates on hormone-induced intracellular responses after eLH/CG-R activation has never been studied.

In order to study the structure-function relationship of $\mathrm{eLH}$ and eCG in a homologous system, we undertook the cloning of the complete nucleotide sequence and the functional expression of the eLH/CG-R cDNA, and studied the binding activity and hormone-stimulated cAMP production of the recombinant eLH/CG-R expressed in COS-7 cells.

\section{Materials and Methods}

\section{Tissue collection and RNA isolation}

Luteal tissues were obtained from one cyclic mare at day 8 post-ovulation and from three mares at days 15, 42 and 61 of pregnancy after ovariectomy as previously described (Saint-Dizier et al. 2003), and in accordance with the International Guiding Principles for Biomedical Research Involving Animals as promulgated by the Society for the Study of Reproduction. Total RNA was extracted from fragments of frozen tissue using Trizol reagent (Invitrogen Life Technologies) according to the manufacturer's instructions. The resulting RNA was quantified spectrophotometrically and stored at $-80{ }^{\circ} \mathrm{C}$ until required for use.

\section{Isolation and sequencing of full-length eLH/CG-R cDNA}

Total pooled RNA $(2 \mu \mathrm{g})$ was reverse transcribed into first-strand cDNA using oligo(dT) primer and Rnase H-reverse transcriptase (Superscript II; Invitrogen Life Technologies) in the presence of deoxynucleotides according to the manufacturer's recommendations. A 646 base pair (bp) cDNA fragment (cDNA fragment 1) encoding a part of the extracellular domain of the eLH/CG-R was first generated using primer pair P1 and P2 based on cDNA sequences similar among bovine (Lussier et al. 1996), porcine (Loosfelt et al. 1989), human (Minegishi et al. 1990) and murine (McFarland et al. 1989) LH/ CG-Rs (Table 1). First-strand cDNA was subjected to 30 cycles of PCR amplification using Advantage 2 polymerase mix (BD Biosciences, Palo Alto, CA, USA) and primer pair $\mathrm{P} 1$ and $\mathrm{P} 2$. The reaction times were $1 \mathrm{~min}$ denaturation at $95^{\circ} \mathrm{C}$ for the first cycle and $15 \mathrm{~s}$ per cycle thereafter, $40 \mathrm{~s}$ annealing at $60{ }^{\circ} \mathrm{C}$ and $1 \mathrm{~min}$ extension at $72{ }^{\circ} \mathrm{C}$ for the first 29 cycles, and $10 \mathrm{~min}$ extension on the final cycle at $72{ }^{\circ} \mathrm{C}$. The $3^{\prime}$-end of the eLH/CG-R cDNA (cDNA fragment 2) was subsequently isolated using sense primer P3 designed from the cDNA fragment 1 previously obtained and a degenerate antisense primer (P4) based on bovine, porcine and human LH/CG-R cDNA sequences (Table 1). First-strand cDNA was amplified for 30 cycles using Advantage 2 polymerase mix (BD Biosciences) and primer pair $\mathrm{P} 3$ and $\mathrm{P} 4$ in the PCR conditions described above. Finally, the $5^{\prime}$-end of the eLH/CG-R cDNA (cDNA fragment 3) was isolated using the antisense primer P5 designed from the cDNA fragment 1 (Table 1) and the rapid amplification of cDNA ends technique, as described previously (Saint-Dizier et al. 2004). 
All amplified PCR products were subcloned into the TA (thymine adenine) cloning vector pCR II-TOPO (Invitrogen Life Technologies) and sequenced on both strands (Genome Express, Meylan, France). Sequence analyses were performed on the Infobiogen web site (http://www.infobiogen.fr).

\section{Construction of the eLH/CG-R $c D N A$ for expression studies}

Comparison of the $468 \mathrm{bp}$ cDNA fragment 3 with cDNA sequences of other mammalian LH/CG-Rs showed that this fragment encoded a partial signal peptide followed by the N-terminal extremity of the eLH/CG-R mature protein. Because of the high homology between the eLH/CG-R cDNA fragment 3 and the corresponding porcine LH/CG-R cDNA (93\%; Loosfelt et al. 1989), a chimeric porcine/equine signal peptide was engineered to permit receptor expression at the membrane level (Fig. 1A). The nucleic acid sequence of this porcine/equine signal peptide was added to the $5^{\prime}$-end of the cDNA fragment 3 by PCR using a sense primer P6 (Table 1) and the antisense primer $\mathrm{P} 5$ under the following conditions: $1 \mathrm{~min}$ at $94{ }^{\circ} \mathrm{C}$ for one cycle; $1 \mathrm{~min}$ at $94^{\circ} \mathrm{C}, 1 \mathrm{~min}$ at $52{ }^{\circ} \mathrm{C}$ and $1 \mathrm{~min}$ at $72{ }^{\circ} \mathrm{C}$ for 25 cycles, and $10 \mathrm{~min}$ at $72{ }^{\circ} \mathrm{C}$ for one cycle. The $533 \mathrm{bp}$ PCR product obtained (cDNA fragment $3^{\prime}$ ) was purified, cloned into the TA cloning vector pCR II-TOPO (Invitrogen Life Technologies) and sequenced.

A full-length eLH/CG-R cDNA was engineered by fusing the overlapping fragments 1 and 2 at the unique site PstI, generating a $1483 \mathrm{bp}$ fragment $(1+2)$, and then fusing the overlapping fragments $(1+2)$ and $3^{\prime}$ at the unique site BglII (Fig. 1B). The resulting 2112 bp cDNA was cloned into the XbaI site of pCDNA 3.1 (+), a eukaryotic expression vector (Invitrogen Life Technologies), to yield pCDNA-eLH/CG-R. All the constructs were amplified in chemically competent Escherichia coli TOP 10 (Invitrogen Life Technologies), purified using the Nucleobond AX maxiprep plasmid kit and sequenced.

\section{Transient transfection of COS-7 cells}

COS-7 monkey kidney cells were maintained at $37^{\circ} \mathrm{C}$ in a humidified 5\% $\mathrm{CO}_{2}$ incubator in Dulbecco's modified Eagle's medium (DMEM) supplemented with 10\% fetal calf serum (FCS), $100 \mathrm{IU} / \mathrm{ml}$ penicillin, $100 \mu \mathrm{g} / \mathrm{ml}$ streptomycin, $2 \mathrm{mM}$ L-glutamine and $10 \mathrm{mM}$ Hepes. They were transfected at $65 \%$ confluency in $10 \mathrm{~cm}$ diameter Petri dishes with $12 \mu \mathrm{g}$ pCDNA-eLH/CG-R using a calcium phosphate precipitation procedure previously described by Chopineau et al. (1997). For four dishes, $124 \mu \mathrm{l}$ $2 \mathrm{M} \mathrm{CaCl}_{2}$ was mixed with $48 \mu \mathrm{g}$ pCDNA-eLH/CG-R and the volume adjusted to $1 \mathrm{ml}$ with water. A DNA precipitate was formed by adding the mixture drop by drop to $1 \mathrm{ml}$ Hepes-buffered saline (HBS) and $500 \mu \mathrm{l}$ was then added to each Petri dish, followed by incubation for $4 \mathrm{~h}$. The medium containing DNA and calcium was then

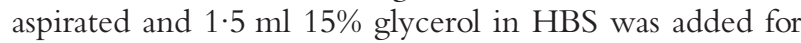
$90 \mathrm{~s}$. The cells were then rinsed before being incubated with $6 \mathrm{ml}$ supplemented DMEM for $48 \mathrm{~h}$. Mocktransfected cells were treated in the same manner but without DNA, and control cells were transfected with the expression vector pCDNA without insert.

\section{Homologous radioreceptor assays}

Crude membrane preparations were made from transfected cells using a method previously described by Richard et al. (1997). Briefly, transiently transfected COS-7 cells in each Petri dish were washed with PBS $\left(1 \cdot 1 \mathrm{mM} \mathrm{KH}_{2} \mathrm{PO}_{4}, 8 \cdot 1 \mathrm{mM} \mathrm{Na}_{2} \mathrm{HPO}_{4}, 134 \mathrm{mM} \mathrm{NaCl}\right)$, then disrupted by thermic shock $\left(5 \mathrm{~min}\right.$ at $37^{\circ} \mathrm{C}$ then $5 \mathrm{~min}$ at $\left.-80^{\circ} \mathrm{C}\right)$ in $1 \mathrm{ml}$ buffer A $(10 \mathrm{mM}$ Tris- $\mathrm{HCl}$, $\mathrm{pH} 7 \cdot 4,0 \cdot 1 \%$ BSA, $20 \%$ glycerol) supplemented with one tablet of protease inhibitors cocktail (Complete Mini, Roche Diagnostics), and collected by centrifugation for $30 \mathrm{~min}$ at $10000 \mathrm{~g}$. The pellets were resuspensed in $1 \mathrm{ml}$ buffer B (10 mM Tris-HCl, pH 7•4, 0·1\% BSA), pooled, then aliquoted in smaller volumes and stored at $-80{ }^{\circ} \mathrm{C}$ until required for use as binding fractions. The protein concentration of COS-7 binding fractions was determined by the method of Bradford (1976).

Homologous equine radioreceptor assays were performed on COS-7 binding fractions according to a method previously described for equine luteal membranes (SaintDizier et al. 2003). Equine LH (National Hormone and Peptide Program, lot no. AFP5130A) was radioactively labelled with ${ }^{125} \mathrm{I}-\mathrm{Na}$ (Amersham Pharmacia Biotech) using Iodo-Gen (Pierce, Rockford, IL, USA). The specific activity of ${ }^{125} \mathrm{I}-\mathrm{eLH}(2100 \mathrm{Ci} / \mathrm{mmol}$; molecular weight (MW) 34 000) was calculated by column recovery as described previously (Bolton \& Hunter 1973). For ${ }^{125} \mathrm{I}-$ eLH-binding displacement assays, crude COS-7 membrane preparations $(15 \mu \mathrm{g}$ proteins/tube) were incubated with a constant amount of ${ }^{125} \mathrm{I}-\mathrm{eLH}(55 \mathrm{pM})$ and increasing amounts of unlabelled eLH, eCG or eFSH. Hormones used were all purified in our laboratory and their relative activities were all as follows: eLH 525, $0.8 \times \mathrm{eLH}-\mathrm{A}$ activity; eCG 652, 5000 IU/mg; (Guillou \& Combarnous 1983, Combarnous et al. 1984). eLH-A and eFSH-A are standard preparations described in these two references. For ${ }^{125} \mathrm{I}$-eLH-binding saturation assays, COS-7 binding fractions were incubated with increasing amount of ${ }^{125} \mathrm{I}$-eLH (seven points from 10 to $600 \mathrm{pM}$ ). Non-specific binding was determined in the presence of 100 IU human chorionic gonadotrophin (hCG; Chorulon, Intervet, Boxmeer, Netherlands). All reactions were incubated in triplicate in a final volume of $300 \mu \mathrm{l}$ buffer B supplemented with $6 \mathrm{mM} \mathrm{CaCl}_{2}$ at room temperature for $18 \mathrm{~h}$. Reactions were stopped by the addition of $1 \mathrm{ml}$ cold buffer $\mathrm{B}$, and bound and free hormones were separated by 
$\mathbf{A}$

Alignment of porcine and equine LH/CG-R N-terminal amino acid sequences

\begin{tabular}{|c|c|c|}
\hline & 20 & 40 \\
\hline $\mathrm{pLH} / \mathrm{CG}-\mathrm{R}$ & MRRRSLALRLLLALLLLPPPLPQTLLG & APCPEPCSCRPDGALRCPGP \\
\hline $\mathrm{eLH} / \mathrm{CG}-\mathrm{R}$ & ------------------- LLPQALRG & APCPEPCRCPPDGALSCPGP \\
\hline
\end{tabular}

Chimeric signal peptide MRRSLALRLILALILLPPLLPQALRG

Deduced nucleic acid sequence of the chimeric signal peptide

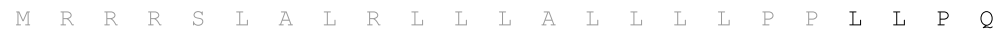
ATGAGAAGAAGGTCACTAGCACTACGACTATTATTGGCACTACTTTTGTTACCACCACTGCTGCCGCAAGC

Nucleic acid sequence of the primer P6

5' GCTCTAGA CGCAAGC $3^{\prime}$

B
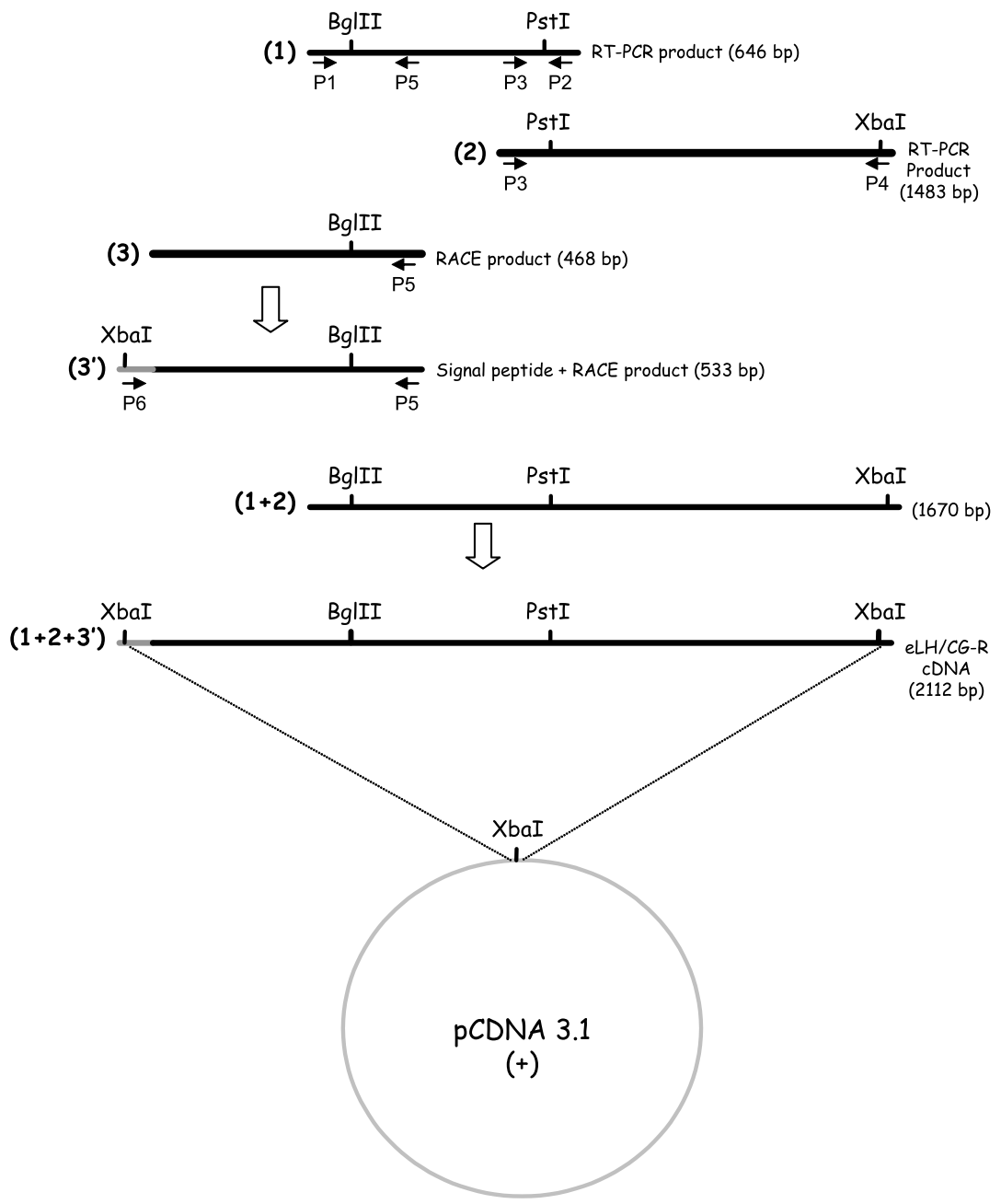
centrifugation at $4000 \mathrm{~g}$ for $30 \mathrm{~min}$ at $4{ }^{\circ} \mathrm{C}$. The resulting pellets were counted in a gamma counter.

The data on displacement and saturation plots were analysed with the GraphPad PRISM2.01 software package (San Diego, CA) in order to estimate the concentration of hormone required to reduce ${ }^{125} \mathrm{I}-\mathrm{eLH}$ binding by $50 \%$ $\left(\mathrm{IC}_{50}\right)$, the equilibrium constant $\left(K_{\mathrm{d}}\right)$ and the maximal binding capacity $\left(\mathrm{B}_{\max }\right)$.

\section{cAMP assays}

Transfected cells were rinsed and placed in DMEM supplemented with $0.1 \%$ BSA (Sigma) and $0.25 \mathrm{mM}$ isobutylmethyl xanthine (Sigma) at $37^{\circ} \mathrm{C}$ for $30 \mathrm{~min}$, then stimulated in triplicate for $1 \mathrm{~h}$ with various concentrations of eLH, eCG and eFSH (eLH 525; eCG 652; eFSH 149) or human recombinant FSH (Gonal-F, Serono, Geneva, Switzerland). cAMP secreted into the extracellular medium was measured using a radioimmunoassay kit according to the manufacturer's instructions (Immunotech, Marseille, France). Briefly, cell supernatants were desiccated, resuspended in $100 \mu \mathrm{l} \mathrm{PBS}$, and incubated overnight with $3 \times 10^{-3} \mu \mathrm{Ci}{ }^{125} \mathrm{I}$-cAMP in anti-cAMP antibody-coated tubes. The supernatants were then removed and the uncompeted radioactivity was counted in a gamma counter. The agonist concentrations inducing half-maximal stimulation of cAMP production $\left(\mathrm{EC}_{50}\right)$ were calculated using the GraphPad PRISM201 software package.

\section{Results and Discussion}

\section{Comparison of the eLH/CG-R with other mammalian $L H / C G-R s$}

Figures 2 and 3 show the nucleotide and deduced amino acid sequences of the cloned eLH/CG-R cDNA, in addition to comparisons between equine, porcine, bovine, human and rat LH/CG-R amino acid sequences. The 2047 bp eLH/CG-R cDNA generated from cDNA fragments 1, 2 and 3 showed 92.3, 91.6, 88 and $85 \cdot 7 \%$ homologies with reported cDNA sequences of porcine (Loosfelt et al. 1989), bovine (Lussier et al. 1996), human
(Minegishi et al. 1990) and rat (McFarland et al. 1989) LH/CG-Rs respectively, and showed $64 \cdot 6 \%$ homology with equine FSH receptor (eFSH-R) cDNA (Robert et al. 1994). The predicted amino acid sequence of the fulllength pCDNA-eLH/CG-R construct consisted of 27 residues of a putative signal peptide followed by 672 residues of a mature protein (Fig. 2). The eLH/CG-R mature protein was highly conserved among mammals (pig $92 \cdot 8 \%$, cow $92 \%$, human $89 \cdot 3 \%$ and rat $88.2 \%$ ) and showed $57 \cdot 9 \%$ homology with the eFSH-R. The putative eLH/CG-R transmembrane domain was composed of 266 amino acids residues, including seven hydrophobic segments potentially spanning the cytoplasmic membrane, followed by a 71 amino acid COOH-terminal intracellular domain.

An interesting finding was a seventh $\mathrm{N}$-glycosylation site $\left(\mathrm{N}^{23}-\mathrm{L}^{24}-\mathrm{S}^{25}\right)$ in the $\mathrm{N}$-terminal extremity of the 335 amino acid extracellular domain of the eLH/CG-R, i.e. one more than the six conserved $\mathrm{N}$-glycosylation sites in the human, porcine, bovine and rat LH/CG-R sequences (Fig. 3) (Loosfelt et al. 1989, McFarland et al. 1989, Minegishi et al. 1990, Lussier et al. 1996). It would be of interest to investigate the possible functional role of this equine-specific $N$-glycosylation in eCG and eLH binding affinities through the use of recombinant eLH/CG-R with the mutated $\mathrm{N}^{23}-\mathrm{L}^{24}-\mathrm{S}^{25}$ site.

\section{Binding activity of recombinant eLH/CG-R expressed in COS- 7 cells}

To confirm that the cloned cDNA encodes a functional LH/CG-R, COS-7 cells were transiently transfected with the pCDNA-eLH/CG-R construct, and crude membrane preparations from the transfected cells were used in a homologous radioligand receptor assay. As shown in Fig. 4, increasing amounts of specific binding of ${ }^{125} \mathrm{I}-\mathrm{eLH}$ were found in membrane preparations from transfected cells incubated with increasing doses of labelled eLH. Analysis of the saturation curve indicated a dissociation constant $\left(K_{\mathrm{d}}\right)$ of $3.8 \times 10^{-10} \mathrm{M}$ and a $\mathrm{B}_{\max }$ of $45.8 \mathrm{fmol} / \mathrm{mg}$ protein. The $K_{\mathrm{d}}$ measured for the recombinant eLH/CG-R was similar to those previously reported for eLH/CG binding sites in equine luteal or

Figure 1 (A) Engineering of a chimeric porcine/equine signal peptide. The $\mathrm{N}$-terminal amino acid sequence of the porcine $\mathrm{LH} / \mathrm{CG}-\mathrm{R}$ $\left(\mathrm{pLH} / \mathrm{CG}-\mathrm{R}\right.$, in grey, Loosfelt et al. 1989) and the translated amino acid sequence of the $5^{\prime}$-end of the eLH/CG-R cDNA fragment 3 were aligned. Potential cleavage sites of porcine and chimeric signal peptides were determined using the SignalP V1.1 program on the ExPASy website (Expert Protein Analysis System; http://www.expasy.org) and are indicated with arrows. No potential cleavage site could be determined for the partial sequence of the eLH/CG-R using this program. The deduced nucleic acid sequence of the chimeric signal peptide was designed using the genetic code and limiting the number of $\mathrm{G}$ and $\mathrm{C}$ bases. The sense primer P6 was used in combination with the antisense primer P5 to add the nucleic acid sequence of the chimeric signal peptide to the $5^{\prime}$-end of the cDNA fragment 3 . The primer P6 was also designed to allow ligation of the full-length eLH/CG-R CDNA into the pCDNA expression vector and thus contained an Xbal restriction site (underlined). (B) Construction of the pCDNA-eLH/CG-R. Horizontal lines indicate cDNA fragments and arrows indicate the different primers used. A full-length eLH/CG-R CDNA was engineered by fusing the overlapping fragments 1 and 2 at the unique site Pstl, generating a $1483 \mathrm{bp}$ fragment $(1+2)$, and then fusing the overlapping fragments $(1+2)$ and $3^{\prime}$ at the unique site Bglll. The resulting 2112 bp cDNA was cloned into the Xbal site of pCDNA $3 \cdot 1(+)$. 


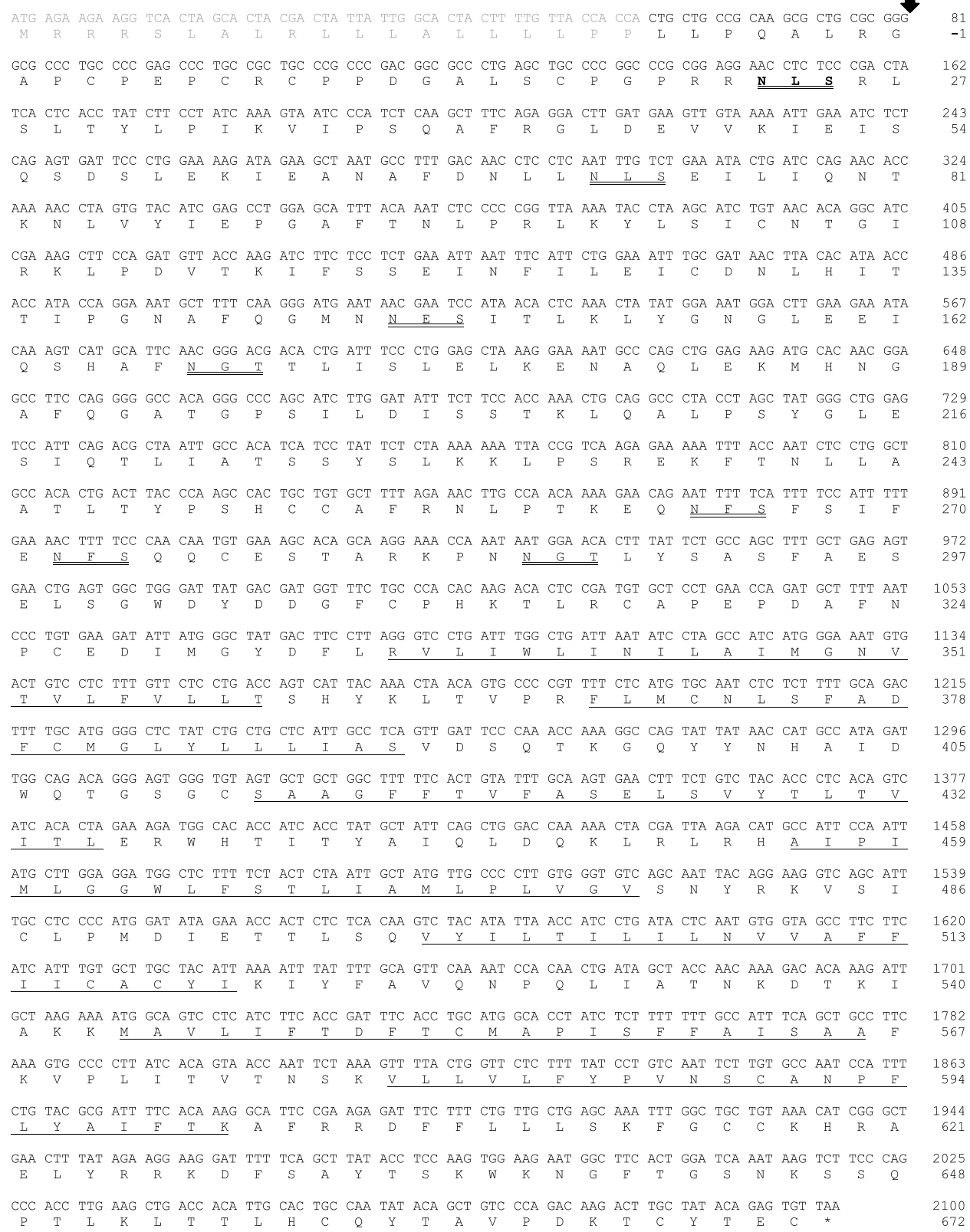

Figure 2 Nucleic acid and deduced amino acid sequences of the recombinant eLH/CG-R expressed in COS-7 cells. The putative cleavage site of the chimeric porcine (grey)/equine peptide signal is indicated by an arrow. The equine-specific $\mathrm{N}$-glycosylation site is indicated in bold letters double underlined; other double underlines indicate the six $N$-linked glycosylation sites conserved among other mammalian LH/CG-Rs. Single underlines indicate the seven predicted transmembrane-spanning domains.

testicular membranes (Evans et al. 1982, Broadley et al. 1994, Motton \& Roser 1997, Saint-Dizier et al. 2003). Mock-transfected cells and cells transfected with the expression vector without insert showed no binding to ${ }^{125} \mathrm{I}-\mathrm{eLH}$.

In order to compare the binding activity of eLH and eCG on recombinant eLH/CG-R, competitive binding studies were performed on membranes from transfected COS-7 cells. As shown in Fig. 5, increasing doses of eLH and eCG competed with the membrane-bound ${ }^{125} \mathrm{I}-\mathrm{eLH}$, which indicates that both eCG and eLH bound to the recombinant eLH/CG-R expressed on COS-7 membranes. However, on a molar basis, eCG ( $\mathrm{IC}_{50} 427 \mathrm{ng} / \mathrm{ml}$; MW 44 000) bound to the recombinant eLH/CG-R with 


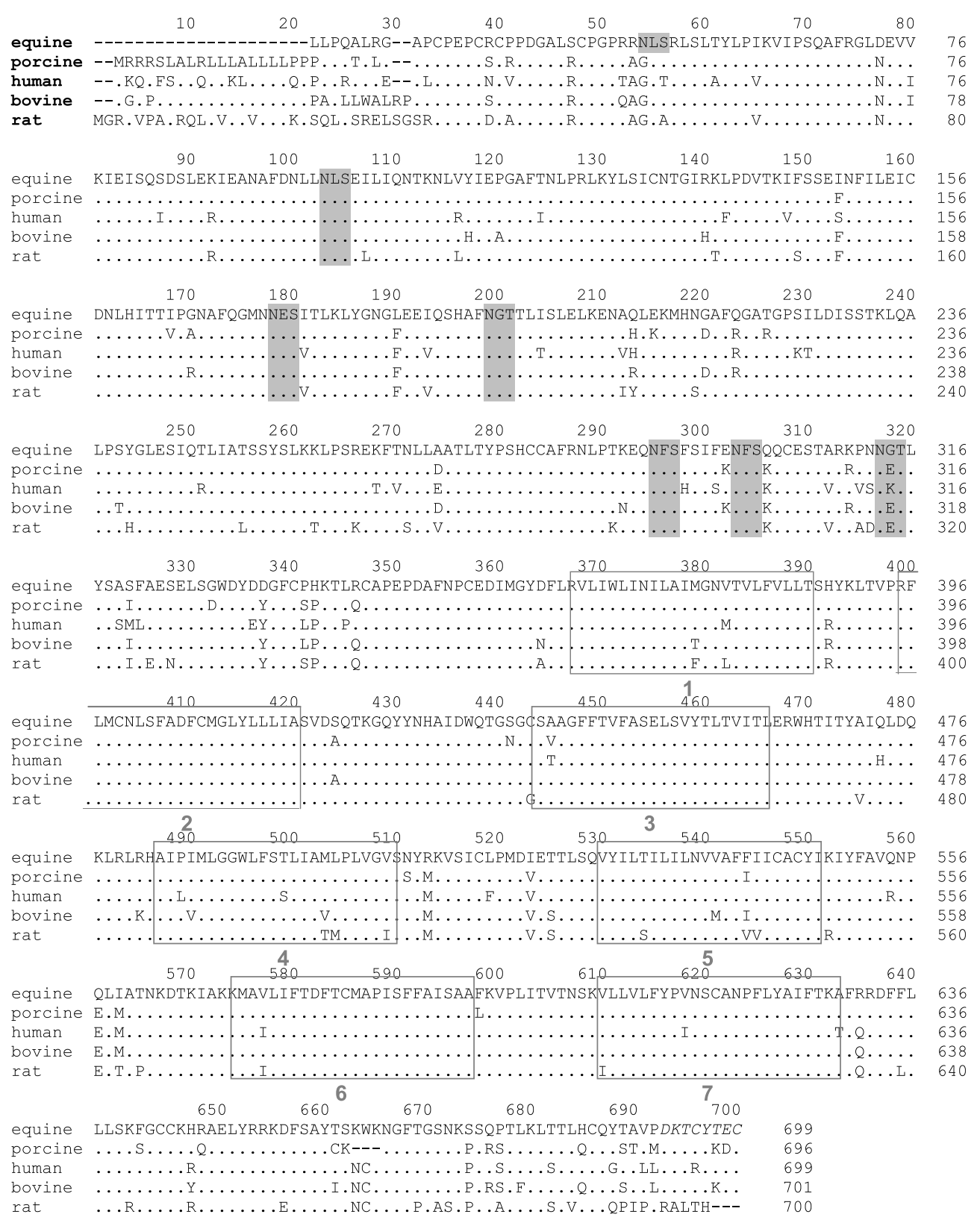

Figure 3 Alignment of the amino acid sequences of equine, porcine, human, bovine and rat $\mathrm{LH} / \mathrm{CG}$ receptors. Dots and dashes indicate identities and gaps respectively. The putative transmembrane domains are boxed. The potential $\mathrm{N}$-glycosylation sites are highlighted in grey. The amino acids deduced from the degenerate $\mathrm{P} 4$ primer at the C-terminal extremity are in italics.

only $12 \cdot 4 \%$ of the binding activity of eLH $\left(\mathrm{IC}_{50} 41 \mathrm{ng} / \mathrm{ml}\right.$; MW 34 000).

The ratio of eCG binding activity to eLH activity for the recombinant eLH/CG-R (12.4\%) was not very different from those previously found in testicular tissue $(4 \%$; Guillou \& Combarnous 1983) and luteal tissue from cyclic (2-4\%; Stewart \& Allen 1979) or pregnant $(2 \cdot 5-3 \cdot 9 \%$;
Saint-Dizier et al. 2003) mares. Thus, as for the native receptor, eLH was found to exhibit much greater affinity than eCG for the recombinant eLH/CG-R expressed in COS-7 cells. As eLH and eCG exhibit similar affinities toward the porcine LH-R (Guillou \& Combarnous 1983), this difference could be attributable to the specific seventh $N$-glycosylation site of the eLH/CG-R. 


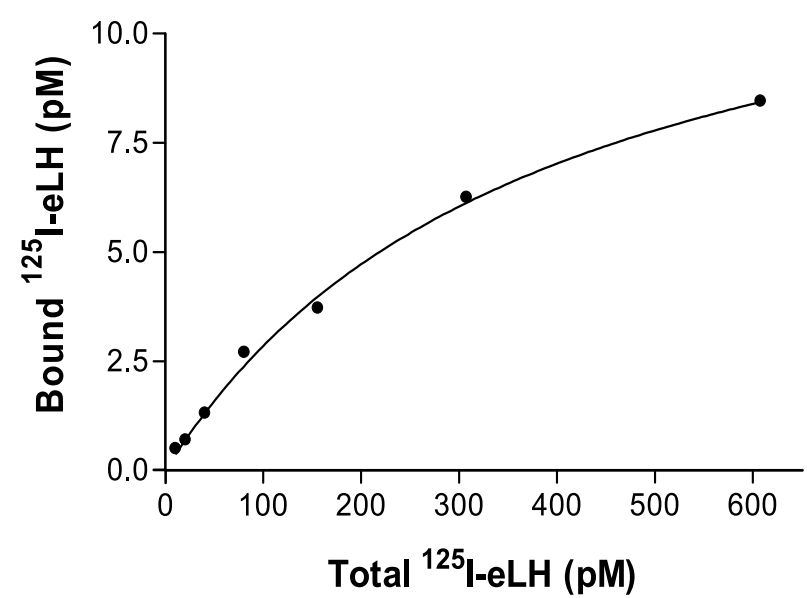

Figure 4 Saturation curve of ${ }^{125} \mathrm{I}$-eLH binding to membrane preparations from COS-7 cells transiently transfected with the pCDNA-eLH/CG-R construct. Cell membranes were incubated in triplicate with ${ }^{125} \mathrm{I}$-eLH in concentrations ranging from 10 to 600 pM with or without 100 IU cold hCG. The experiment was repeated three times and a representative assay is shown.

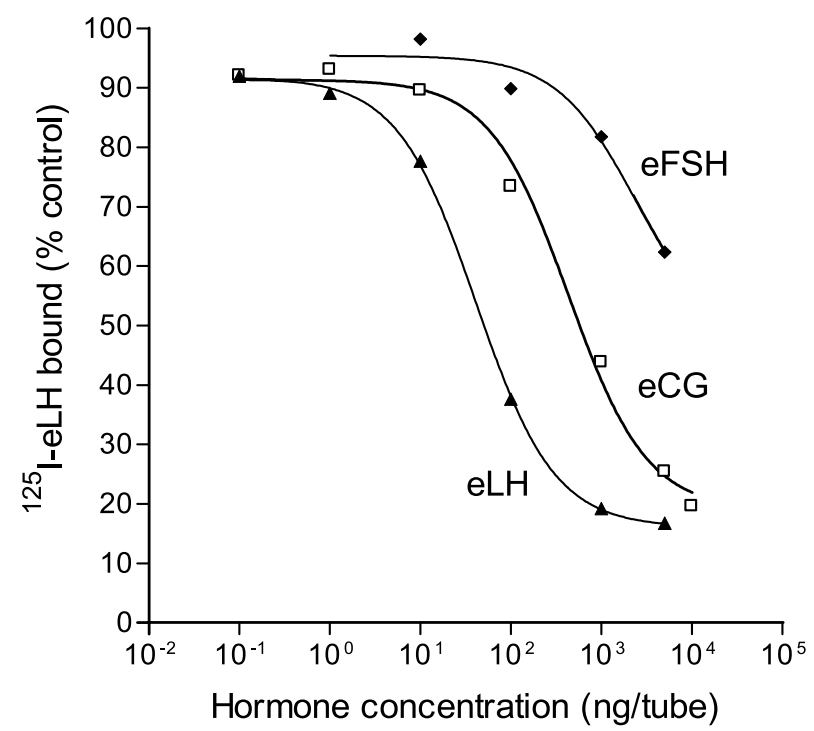

Figure 5 Competition curves of ${ }^{125} \mathrm{I}$-eLH binding to membrane preparations from COS-7 cells transiently transfected with the pCDNA-eLH/CG-R construct. Cell membranes were incubated in triplicate with a constant amount of ${ }^{125} \mathrm{I}$-eLH (55 pM) and increasing concentrations of unlabelled eLH and eCG. The experiment was repeated once and a representative assay is shown.

Gonadotrophin stimulation of cAMP production by transfected COS-7 cells

The ability of the recombinant eLH/CG-R to stimulate the cAMP pathway was tested by challenging the transfected cells with increasing concentrations of eLH and eCG. Stimulation with both hormones resulted in dosedependent increases in cAMP production, which were about 20-fold and 15-fold increased over the basal rate of

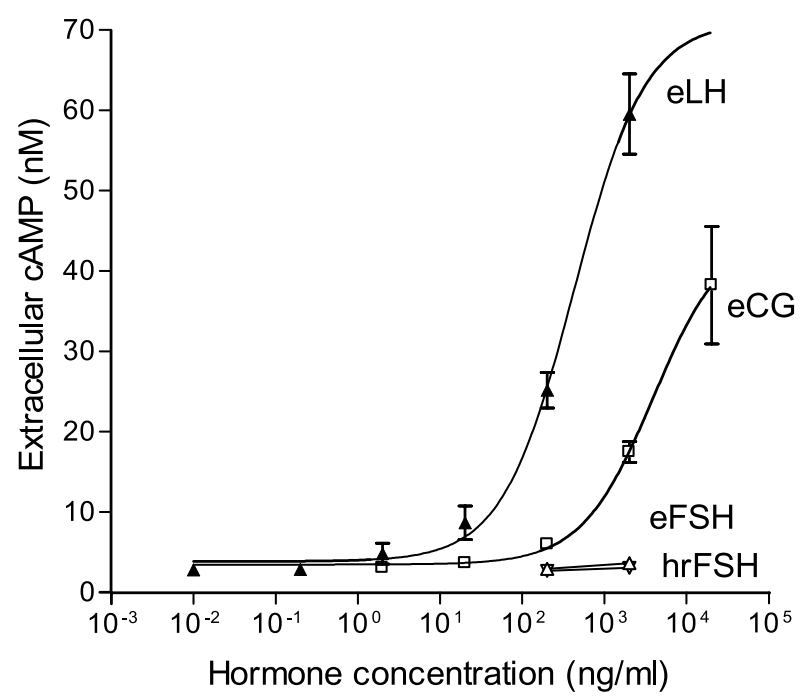

Figure 6 Effect of various gonadotrophins on media cAMP concentrations in COS-7 cells transiently transfected with the pCDNA-eLH/CG-R construct. COS-7 cells were cultured for $1 \mathrm{~h}$ in the presence or absence of increasing doses of eLH, eCG, eFSH or human recombinant FSH (hrFSH). The data are expressed as the mean \pm S.E.M. of triplicate observations from a single experiment. The experiment was repeated once and a representative assay is shown.

production with maximal doses of eLH and eCG respectively (Fig. 6). On a molar basis, eCG (EC $\left.{ }_{50} 3865 \mathrm{ng} / \mathrm{ml}\right)$ stimulated cAMP production with $13.9 \%$ of the stimulating activity of $\mathrm{eLH}\left(\mathrm{EC}_{50} 418 \mathrm{ng} / \mathrm{ml}\right)$. Neither pituitary eFSH nor recombinant hFSH stimulated cAMP production in transfected cells (Fig. 6). Mock-transfected cells and cells transfected with the expression vector without insert showed no increase in cAMP after hormone stimulation (data not shown).

Our results indicate that the binding of both eLH and eCG to the recombinant eLH/CG-R leads to activation of the adenylate cyclase/cAMP pathway, which is the main intracellular signalling pathway activated by mammalian LH/CG-Rs (Dufau 1998, Ascoli et al. 2002). As eLH and eCG have identical polypeptide chains (Bousfield et al. 1987, Sugino et al. 1987), the hormone carbohydrate compositions of eLH and eCG seem to be implicated in the binding affinity of the hormone for the recombinant eLH/CG-R, leading to different degrees of coupled intracellular responses.

In conclusion, the recombinant eLH/CG-R expressed in COS-7 cells provides us with a valuable model with which to study the influence of linked glycan chains on gonadotrophin receptor binding and activation.

\section{Funding}

M S-D was supported by a fellowship from the Institut National de la Recherche Agronomique and the Région 
Centre. The authors declare that there is no conflict of interest that would prejudice the impartiality of this scientific work.

\section{References}

Ascoli M, Fanelli F \& Segaloff DL 2002 The lutropin/ choriogonadotropin receptor, a 2002 perspective. Endocrine Reviews 23 141-174.

Bolton AE \& Hunter WM 1973 The labelling of proteins to high specific radioactivities by conjugation to 125 -I-containing acylating agent. Biochemical Journal 133 529-539.

Bousfield GR, Liu WK, Sugino H \& Ward DN 1987 Structural studies on equine glycoprotein hormones. Amino acid sequence of equine lutropin beta-subunit. Journal of Biological Chemistry 262 8610-8620.

Bousfield GR, Butnev VY, Gotschall RR, Baker VL \& Moore WT 1996 Structural features of mammalian gonadotropins. Molecular and Cellular Endocrinology 125 3-19.

Bousfield GR, Butnev VY \& Butnev VY 2001 Identification of twelve $O$-glycosylation sites in equine chorionic gonadotropin beta and equine luteinizing hormone beta by solid-phase Edman degradation. Biology of Reproduction 64 136-147.

Bradford MM 1976 A rapid and sensitive method for the quantitation of microgram quantities of protein utilizing the principle of protein-dye binding. Analytical Biochemistry 72 248-254.

Broadley C, Menzies GS, Bramley TA \& Watson ED 1994 Isolation of cell populations from the mare corpus luteum: comparison of mechanical and collagenase dissociation. Journal of Reproduction and Fertility 102 7-15.

Butnev VY, Gotschall RR, Baker VL, Moore WT \& Bousfield GR 1996 Negative influence of O-linked oligosaccharides of high molecular weight equine chorionic gonadotropin on its luteinizing hormone and follicle-stimulating hormone receptor-binding activities. Endocrinology 137 2530-2542.

Chopineau M, Martinat N, Troispoux C, Marichatou H, Combarnous Y, Stewart F \& Guillou F 1997 Expression of horse and donkey LH in COS-7 cells: evidence for low FSH activity in donkey LH compared with horse LH. Journal of Endocrinology 152 371-377.

Combarnous Y, Guillou F \& Martinat N 1984 Comparison of in vitro follicle stimulating hormone (FSH) activity of equine gonadotropins (luteinizing hormone, FSH and chorionic gonadotropin) in male and female rats. Endocrinology 115 1821-1827.

Dufau ML 1998 The luteinizing hormone receptor. Annual Review of Physiology 60 461-496.

Evans JW, Roser JF \& Mikuckis GM 1982 Comparison of the interaction of equine $\mathrm{LH}$ and human chorionic gonadotrophin to equine testicular receptors. Journal of Reproduction and Fertility. Supplement 32 113-121.

Guillou F \& Combarnous Y 1983 Purification of equine gonadotropins and comparative study of their acid-dissociation and receptor-binding specificity. Biochimica et Biophysica Acta $\mathbf{7 5 5}$ 229-236.

Licht P, Gallo AB, Aggarwal BB, Farmer SW, Castelino JB \& Papkoff H 1979 Biological and binding activities of equine pituitary gonadotrophins and pregnant mare serum gonadotrophin. Journal of Endocrinology 83 311-322.

Loosfelt H, Misrahi M, Atger M, Salesse R, Vu Hai-Luu Thi MT, Jolivet A, Guiochon-Mantel A, Sar S, Jallal B, Garnier J \& Milgrom E 1989 Cloning and sequencing of porcine LH-hCG receptor cDNA: variants lacking transmembrane domain. Science $\mathbf{2 4 5}$ 525-528.
Lussier JG, Houde A, Ethier J \& Silversides DW 1996

Complementary DNA structure of the bovine LH receptor. Direct submission to Genbank, no. U20504.

McFarland KC, Sprengel R, Phillips HS, Kohler M, Rosemblit N, Nikolics K, Segaloff DL \& Seeburg PH 1989

Lutropin-choriogonadotropin receptor: an unusual member of the $G$ protein-coupled receptor family. Science 245 494-499.

Minegishi T, Nakamura K, Takakura Y, Miyamoto K, Hasegawa Y, Ibuki Y, Igarashi M \& Minegish T 1990 Cloning and sequencing of human LH/hCG receptor cDNA. Biochemical and Biophysical Research Communications 172 1049-1054.

Motton DD \& Roser JF 1997 HCG binding to the testicular LH receptor is similar in fertile, subfertile, and infertile stallions. Journal of Andrology 18 411-416.

Rao CV 1997 Potential novel roles of luteinizing hormone and human chorionic gonadotropin during early pregnancy in women. Early Pregnancy 3 1-9.

Richard F, Martinat N, Remy JJ, Salesse R \& Combarnous Y 1997 Cloning, sequencing and in vitro functional expression of recombinant donkey follicle-stimulating hormone receptor: a new insight into the binding specificity of gonadotrophin receptors. Journal of Molecular Endocrinology 18 193-202.

Robert P, Amsellem S, Christophe S, Benifla JL, Bellet D, Koman A \& Bidart JM 1994 Cloning and sequencing of the equine testicular follitropin receptor. Biochemical and Biophysical Research Communications 201 201-207.

Saint-Dizier M, Chopineau M, Dupont J, Daels PF \& Combarnous Y 2003 Expression and binding activity of luteinizing hormone/chorionic gonadotropin receptors in the primary corpus luteum during early pregnancy in the mare. Biology of Reproduction 69 1743-1749.

Saint-Dizier M, Chopineau M, Dupont J \& Combarnous Y 2004 Expression of the full-length and alternatively spliced equine LH/CG receptor mRNAs in the primary corpus luteum and foetal gonads during pregnancy. Reproduction 128 219-228.

Sherman GB, Wolfe MW, Farmerie TA, Clay CM, Threadgill DS, Sharp DC \& Nilson JH 1992 A single gene encodes the beta-subunits of equine luteinizing hormone and chorionic gonadotropin. Molecular Endocrinology 6 951-959.

Smith PL, Bousfield GR, Kumar S, Fiete D \& Baenziger JU 1993 Equine lutropin and chorionic gonadotropin bear oligosaccharides terminating with SO4-4-GalNAc and Sia $2,3 \mathrm{Gal}$, respectively. Journal of Biological Chemistry 268 795-802.

Stewart F \& Allen WR 1979 The binding of FSH, LH and PMSG to equine gonadal tissues. Journal of Reproduction and Fertility. Supplement 27 431-440.

Stewart F \& Allen WR 1981 Biological functions and receptor binding activities of equine chorionic gonadotrophins. Journal of Reproduction and Fertility 62 527-536.

Stewart F, Thomson JA, Leigh SE \& Warwick JM 1987 Nucleotide (cDNA) sequence encoding the horse gonadotrophin alphasubunit. Journal of Endocrinology 115 341-346.

Sugino H, Bousfield GR, Moore WT \& Ward DN 1987 Structural studies on equine glycoprotein hormones. Amino acid sequence of equine chorionic gonadotropin beta-subunit. Journal of Biological Chemistry 262 8603-8609.

Themmen APN \& Huhtaniemi IT 2000 Mutations of gonadotropins and gonadotropin receptors: elucidating the physiology and pathophysiology of pituitary-gonadal function. Endocrine Reviews 21 $551-583$.

Received 26 August 2004

Accepted 10 September 2004 